\title{
INSTITUTIONS FOR THE TUBERCULOUS.
}

\section{THE SEAFORTH SANATORIUM, ROSS-SHIRE, SCOTLAND.}

Through the munificence of Colonel Stewart Mackenzie, of Seaforth, and Mrs. Stewart Mackenzie, the North of Scotland has been provided with a modern, fully equipped and adequately endowed sanatorium for the treatment of consumptives. The cost amounted to $£ 8,000$, and



THE SEAFORTH SANATORIUM, ROSS-SHIRE, SCOTLAND.

it has been endowed with $£$ Ioo,ooo. The building has been designed by Mr. Robert J. Macbeth, F.R.I.B.A., of Inverness, after the plan of the Brompton Hospital Sanatorium at Frimley. The sanatorium is admirably placed on the Brahan Estate, on the west side of Maryburgh, not far from Dingwall. It has a south aspect overlooking Cromarty Firth, and is surrounded by well-wooded and otherwise protected lands excellently adapted for the needs of the patients. As indicated in the accompanying illustration and plan, the buildings consist of two detached blocks. The front block contains the patients' rooms and quarters for the administrative staff. The central part is three stories in extent, and 
here are placed matron's and nurses' rooms and the consulting-rooms and dispensary. Accommodation is provided for twelve cases, but is capable of expansion. Each patient has a separate room. The south front has an extent of 184 feet, and provides an excellent sheltered promenade and resting-ground for patients. The north block contains the dining-hall, serving pantry, kitchen, stores, and laundry. The buildings throughout are lit by electricity. A plentiful supply of pure water is available. Sewage is discharged direct into tidal waters. In every respect the institution is fully equipped for the work it is about to undertake. The sanatorium is restricted to natives of Ross-shire.

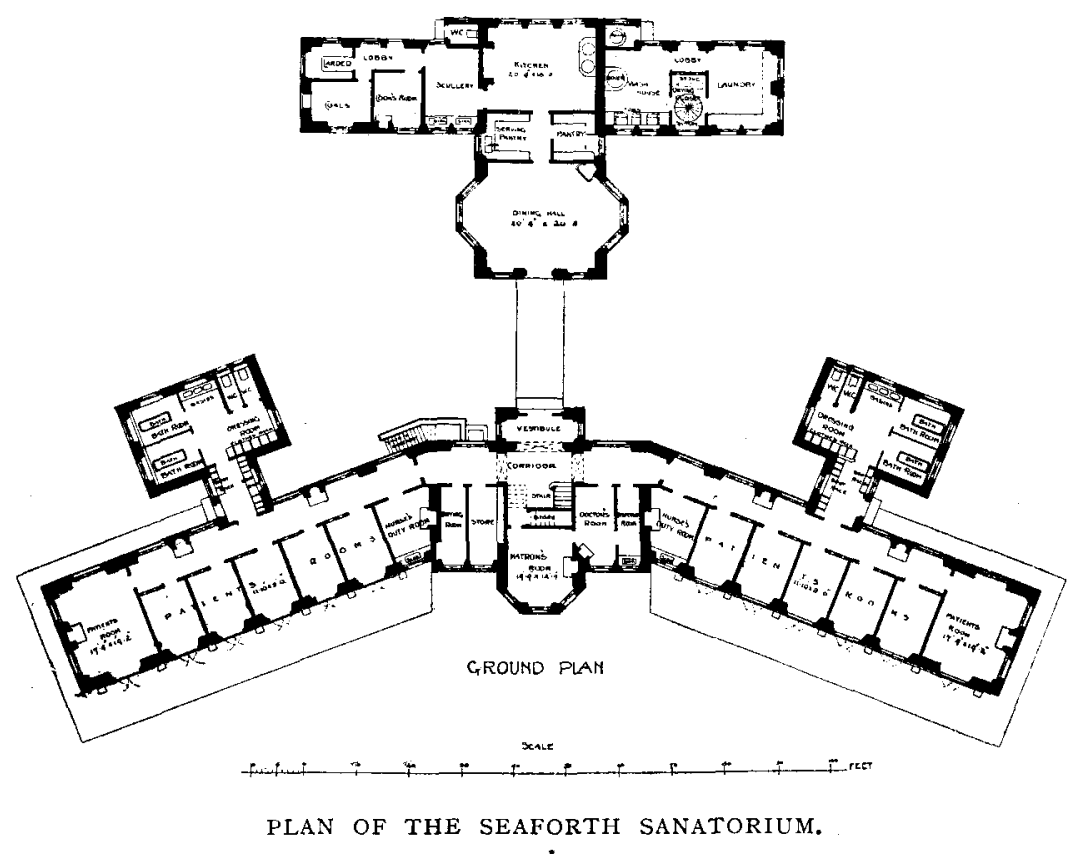

Admission is absolutely free, but only such cases will be admitted as are approved by the medical staff. The sanatorium is to be reserved for incipient cases. It is expected that the educational influence of the establishment will be far-reaching, and it is hoped that valuable research work may be undertaken. There is every reason to believe that this latest addition to the sanatoria of Scotland will accomplish much towards exterminating what is a veritable scourge to large numbers of the dwellers in these northerly regions of Great Britain.

$$
\begin{aligned}
& \text { W. MacLean, M.B., C.M., D.P.H., } \\
& \text { Medical Superintendent. }
\end{aligned}
$$

